\title{
La Gestión Sociocultural para el Desarrollo en Cuba y Brasil: un Estudio desde el Derecho Constitucional Cultural ${ }^{1}$
}

\author{
Sociocultural Management for Development in Cuba and \\ Brazil: a Cultural Constitutional Law's Study
}

\section{Gestão Sociocultural para o Desenvolvimento em Cuba e Brasil: um Estudo do Direito Constitucional à Cultura}

\author{
Ana Elisa Gorgoso Vázquez* \\ Alcides Francisco Antúnez Sánchez ${ }^{* *}$ \\ Magno Federici Gomes
}

\begin{abstract}
1 Introducción. 2 Los estudios de la carrera de gestión sociocultural para el desarrollo en la formación universitaria. 3 La cultura, el derecho cultural y los derechos culturales. 3.1 Reconocimiento de la cultura como derecho constitucional en el Estado de Derecho en Cuba. 3.2 La formación de la cultura jurídica en la carrera de gestión sociocultural para el desarrollo desde el Derecho Constitucional Cultural. 4 Conclusiones. Referencias
\end{abstract}

\footnotetext{
El artículo es el resultado de un trabajo colaborativo entre la carrera de Derecho y la de Gestión sociocultural para el desarrollo, desde una mirada desde las ciencias pedagógicas a través de la didáctica de integración de contenidos desde las ciencias sociales para la presentación de la defensa de la asignatura optativa en ambas carreras al Consejo Científico de la Universidad de Granma y con el análisis de como concurre en Brasil. Este trabajo se ha beneficiado del Edicto no 03/2019 de Fomento a la Investigación de la Escola Superior Dom Helder Camara, resultante de los Grupos de Investigación del CNPQ: Responsabilidad Civil e Proceso Ambiental (RECIPRO), NEGESP, Metamorfose Juridica e CEDIS (FCT-PT).

Máster en Desarrollo Cultural Comunitario. Profesora Auxiliar en la carrera gestión sociocultural para el desarrollo. Facultad de Ciencias Económicas y Sociales. Universidad de Granma. República de Cuba. Email: <agorgosov@udg.co.cu>. ORCID No. 0000-0001-8207-2902

** Máster en Asesoría Jurídica mención Derecho Administrativo Ambiental por la Facultad de Derecho. Universidad de Oriente. Profesor Auxiliar Derecho Ambiental e Internacional Público. Facultad de Ciencias Económicas y Sociales. Universidad de Granma. República de Cuba. Email: <aantunez@udg.co.cu>. ORCID No. 0000-0002-8561-6837 Currículo hospedado en Cielo Laboral. Italia.

*** Prácticas postdoctorales en Derecho Público y Educación en la Universidade Nova de Lisboa-Portugal (Beca CAPES/BEX 3642/07-0). Prácticas postdoctorales en Derecho Civil y Derecho Procesal Civil, Doctor en Derecho y Máster en Derecho Procesal por la Universidad de Deusto-España (Beca de la Cátedra UNESCO y del Gobierno Vasco-España). Máster en Educación por la PUC de Minas. Coordinador y Profesor del Doctorado y del Máster Académico en Derecho Ambiental y Desarrollo Sostenible de la Escola Superior Dom Helder Câmara. Profesor licenciado en la Faculdade de Direito Arnaldo Janssen. Abogado Asociado en Escritório Moraes \& Federici Advocacia Associada. Líder del Grupo de Investigación: Responsabilidade Civil e Processo Ambiental (RECIPRO)/CNPQ-BRA y miembro de los grupos: Centro de Investigación y Desarrollo en Derecho y Sociedad (CEDIS)/FCT-PT, Centro de Estudios de Gestión de Políticas Públicas (NEGESP)/CNPQ-BRA y Metamorfose Jurídica/CNPQ-BRA. ORCID No. 0000-0002-4711-5310. Currículo Lattes: http://lattes.cnpa.br/1638327245727283. E-mail: <magnofederici@gmail.com>.
} 
La gestión sociocultural para el desarrollo en Cuba y Brasil: un estudio desde el derecho constitucional cultural

\section{RESUMEN}

Objetivo: La Constitución Cultural, consagra los derechos culturales a nivel normativo, como normativización constitucional de valores, principios y reglas orientan la acción en ese ámbito específico del ciudadano en un Estado de Derecho. Requerida de normas jurídicas que la complementen y den las garantías a los derechos culturales por el Estado de Derecho en los ordenamientos jurídicos como fuente de identidad en el desarrollo humano. El objetivo principal del artículo es demostrar a partir de la caracterización realizada de los Derechos Constitucionales Culturales, la pertinencia de la formación jurídica en la carrera de gestión sociocultural para el desarrollo de impartir contenidos en una asignatura Derecho Cultural, en atención a las exigencias del Plan de estudios e de la carrera en la formación de valores concomitantes con la identidad nacional desde el modo de actuación profesional por el Ministerio de Educación Superior de Cuba con la actualización del texto constitucional en 2019.

Metodología: La investigación a partir del análisis bibliográfico realizado, permitió conocer que se requiere desarrollar normas jurídicas que la complementen y den las garantías adecuadas a los derechos culturales por el Estado de Derecho como fuente de identidad en el desarrollo humano.

Resultados: Se demostró la necesidad de impartir contenidos en una asignatura optativa Derecho Cultural, en atención a las exigencias del Plan de estudios E de la carrera de gestión sociocultural concomitantes con la identidad nacional desde el modo de actuación profesional establecido por el Ministerio de Educación Superior de la República de Cuba.

Contribuciones: La carrera de gestión sociocultural para el desarrollo tributará con la asignatura Derecho Cultural a la formación de valores en los estudiantes, potenciará la cultura y la identidad nacional desde su modo de actuación como gestor cultural, incidente en el desarrollo humano, social y cultural a través de acciones de capacitación, asesoría, mediación, investigación y facilitación en los escenarios en que interactúa.

Palabras claves: derechos culturales; desarrollo; gestión; garantías.

\section{ABSTRACT}

Objective: The Cultural Constitution establishes cultural rights at a normative level, with the constitutional affirmation of values, principles and norms that guide the actions of citizenship in a Rule of Law. Legal norms require that they complement and guarantee cultural rights through the rule of law in legal systems, as a source of identity in human development. The main objective of the paper is to demonstrate, based on the characterization of the Cultural Constitutional Decrees, the relevance of legal training in the course of sociocultural management for the development and sharing of contents under the name of Cultural Decree, in view of the requirements of the plan teaching and course in the formation of values concomitant to national identity, based on the actions of the Ministry of Higher Education of Cuba, with the updating of the constitutional text in 2019. 
Methodology: The research was based on bibliographic analysis and allowed us to know that it is necessary to develop legal norms that complement and provide adequate guarantees to cultural rights through the Rule of Law, as a source of identity in human development.

Results: The need to teach content was demonstrated through the creation of the optional subject of Cultural Law, meeting the requirements of the teaching plan and the sociocultural management course, concomitant with the national identity of the modality of professional practice established by the Ministry of Higher Education of Republic of Cuba.

Contributions: The course on sociocultural management for development will contemplate, with the Cultural Law discipline, the formation of axioms in students, as well as will value culture and national identity, based on its way of acting as cultural and social manager (incident in human being). Furthermore, it will foster cultural development through training, advisory, mediation, research and facilitation actions in the scenarios in which it will interact.

Keywords: cultural law; development; management; warranties.

\section{RESUMO}

Objetivo: A Constituição Cultural estabelece os direitos culturais em nível normativo, com a positivação constitucional de valores, princípios e normas que orientam a ação da cidadania em um Estado de Direito. As normas jurídicas exigem que complementem e outorguem garantias aos direitos culturais pelo Estado de Direito nos sistemas jurídicos, como fonte de identidade no desenvolvimento humano. O principal objetivo do artigo é demonstrar, com base na caracterização dos Decretos Constitucionais Culturais, a relevância da formação jurídica no curso de gestão sociocultural para o desenvolvimento e, ainda, a partilha de conteúdos sob a denominação de Decreto Cultural, tendo em vista os requisitos do plano de ensino e do curso na formação de valores concomitantes à identidade nacional, a partir da atuação do Ministério da Educação Superior de Cuba, com a atualização do texto constitucional em 2019.

Metodologia: A pesquisa foi baseada na análise bibliográfica e nos permitiu saber que é necessário desenvolver normas jurídicas que a complementem e deem garantias adequadas aos direitos culturais pelo Estado de Direito, como fonte de identidade no desenvolvimento humano.

Resultados: Ficou demonstrada a necessidade de lecionar conteúdos por meio da criação da disciplina optativa de Direito Cultural, atendendo aos requisitos do plano de ensino e do curso de gestão sociocultural, concomitante à identidade nacional da modalidade de atuação profissional instituída pelo Ministério da Educação Superior da República de Cuba.

Contribuições: $\mathrm{O}$ curso de gestão sociocultural para o desenvolvimento contemplará, com a disciplina Direito Cultural, a formação de axiomas nos alunos, bem como valorizará a cultura e a identidade nacional, a partir de seu modo de atuação como 
La gestión sociocultural para el desarrollo en Cuba y Brasil: un estudio desde el derecho constitucional cultural

gestor sociocultural (incidente no ser humano). Ademais, fomentará o desenvolvimento cultural através de ações de capacitação, assessoria, mediação, pesquisa e facilitação nos cenários em que venha a interagir.

Palavras-chave: direito cultural; desenvolvimento; gestão; garantias.

\section{INTRODUCCIÓN}

En la esfera cultural se reconoce el potencial que posee la cultura en su rol que tiene en la defensa de la identidad en una nación, de los valores sociales que aporta, de la conservación del patrimonio cultural, de la creación artística y literaria, en la capacidad para apreciar el arte, tal y como lo refrendan los lineamientos en la nación cubana en la actualización del modelo económico y social en el siglo XXI: fomentar la identidad nacional cubana.

En la nación cubana perviven instituciones culturales del sistema empresarial estatal presupuesta y el no estatal, cumplen un rol en el desarrollo de la producción cultural del país como actores. A estas se les incorpora un entramado de asociaciones de creadores y promotores culturales con distintas estructuras y funciones, ONG, proyectos culturales independientes y Fundaciones, en la reproducción de bienes y servicios culturales incidentes en la formación de la identidad nacional bajo un ordenamiento jurídico.

El proceso de transformación del modelo económico y social cubano en el siglo XXI es un momento propicio para repensar el papel que le corresponde a la creación cultural. Reflexionar sobre el rol de las instituciones estatales, entre su regulación jurídica y la promoción cultural, y los otros actores como instituciones culturales sin fines de lucro y otros espacios de gestión cultural, que son producto de una renovada relación entre el Estado, los mercados y la sociedad (GARCÍA LORENZO, 2014).

La carrera Licenciatura en Estudios Socioculturales, ubicada en el área de las llamadas humanidades, planteó desde su inicio, formar un profesional de perfil amplio, que diera respuesta a la pertinencia, calidad y al proceso de internacionalización propio de la educación superior de nuestros tiempos, fue diseñada a partir de la conjunción de varias carreras ya establecidas en el contexto de la enseñanza superior en Cuba por el Ministerio de Educación Superior (MES), en 2017.

La Constitución cultural, consagra los derechos culturales en el nivel normativo de los ciudadanos, es la normativización constitucional de valores, principios y reglas que orientan la acción en ese ámbito específico del ciudadano como derecho humano. Pero estas pautas necesitan de normas jurídicas que la complementen y den las garantías a los derechos culturales por el Estado de Derecho en los ordenamientos jurídicos a 
partir del texto constitucional, promulgado en el 2019. Es a la vez concebida como una fuente de identidad nacional en el desarrollo humano.

\section{LOS ESTUDIOS DE LA CARRERA DE GESTIÓN SOCIOCULTURAL PARA EL DESARROLLO EN LA FORMACIÓN UNIVERSITARIA}

A partir del juicio de los articulistas, se parte de analizar las bases del concepto de universidad aportado por la UNESCO (2010) en el Sistema de Naciones Unidas para los Estados desde el Derecho Internacional, se precia como reflejan una obligada integración disciplinar de saberes, como el sustento para la formación humanista del individuo, y como la herramienta para el desarrollo de sus potencialidades en función de su posterior desempeño profesional con competencias en beneficio del desarrollo social y cultural -sustentable y sostenible- de los grupos o comunidades a los que responde desde su modo de actuación. Estas bases, se hace la valoración que están en correspondencia con los objetivos del milenio para alcanzar la meta en el 2030.

En consecuencia a esta política internacional aludida, para la formación universitaria, la gestión sociocultural -desde la percepción científica multidisciplinardebe tener como base estrategias encaminadas a la transformación y el mejoramiento social y espiritual de los individuos de manera que, se potencien sus habilidades creativas y culturales -sin desconocer las contradicciones inherentes a las colectividades donde ellas se generan- y se preserven las tradiciones y el patrimonio cultural como la expresión de la identidad local y nacional y, en ocasiones, también como la expresión de lo universal en la presencia de las fusiones y confluencias étnicas, y de los sincretismos religiosos del país, en particular para el desarrollo del turismo desde lo endógeno como en lo exógeno en Cuba y porque que no en otros contextos foráneos.

En el estudio para conformar el artículo, se aprecia en la indagación bibliográfica realizada, donde se afirma que la formación en gestión cultural latinoamericana tiene sus antecedentes de la española como su referente histórico, en particular con ascendencia de la cultura catalana, con algunas influencias francesas y anglosajonas, a partir de los aportes de Stavenhagen (2002), Ávila Ortiz (2002).

Se analiza, como en la ciudad de Barcelona fueron desarrolladas algunas estrategias de internacionalización alrededor de la década de los 90' del pasado siglo XX desde Europa, estos elementos la convirtieron en la meca cultural exportadora de su modelo urbanístico y de gestión cultural que hoy se conoce en América Latina en este etapa.

Conllevan a estudiar el juicio aportado por Martinell Sampere (2001), quien en

su libro "La gestión cultural: singularidad profesional y perspectivas de futuro", refiere en sus análisis que [...] la gestión cultural no es una ciencia, ni se puede contemplar dentro de un marco epistemológico propio, sino que es fruto de un encargo social que 
La gestión sociocultural para el desarrollo en Cuba y Brasil: un estudio desde el derecho constitucional cultural

profesionaliza a un número considerable de personas en respuesta a unas necesidades de una sociedad compleja. Esto le da una perspectiva pluridisciplinar [...] pero reclama que el propio sector realice las aproximaciones necesarias para la construcción de un marco teórico y conceptual de acuerdo con las propias necesidades de esta función.

Son estudiados los aportes de Martínez Casanova, quien desde su posición considera que la gestión sociocultural “(...) es una modalidad de intervención, caracterizada por la gestión movilizadora y transformadora que se hace con recursos socioculturales. (...) la gestión puede hacerse fundamentalmente en y desde instituciones, culturales o no, y comunidades" (MARTÍNEZ CASANOVA, 2015 apud BORGES MACHÍN; ZURBANO COBAS; CASTRO ACEVEDO, 2019, p. 5).

Desde otra perspectiva Borges Machín, valora desde su investigación que, la gestión sociocultural es el proceso realizado con recursos culturales, en su sentido más amplio, dirigido a propiciar, como proceso transformador y de manera progresiva, sostenida e inclusiva, el desarrollo social, principalmente local y comunitario. Se centra en una lógica de planeación, organización, dirección, colaboración, mediación, concertación y control de las acciones, con enfoque multidisciplinar, multilateral y participativo, propiciando la inclusión de todos los sujetos sociales individuales y colectivos, implicados. Se parte, además, del criterio de que estos procesos son pertinentes sólo si integran sostenidamente, acciones de investigación, evaluación, asesoría, capacitación, facilitación, mediación y sistematización (BORGES MACHÍN, 2018).

También en otro sentido, es estudiado Celeiro Carbonell, quien considera en su análisis que la moral y la ética no nacen con el hombre, como cristalizaciones y productos culturales no están encarnados en él, sino en el mundo que los rodea; de esta forma, sólo en el proceso de asimilación él adquiere los conocimientos, las capacidades, las habilidades y los convierte en propios, y esto es posible cuando entra en relación con el mundo a través de otras personas, lo cual, según Leontiev es un proceso de educación (CELEIRO CARBONELL, 2012).

Permite confirmar estas posturas estudiadas que esta influencia de la gestión sociocultural, trascendió a la región de América Latina, donde hay tradición de prácticas de acción cultural enfocadas al trabajo comunitario, como la animación sociocultural, la promoción cultural y la mediación cultural. La emergencia de un nuevo campo de la gestión cultural trasciende al involucrar a la academia, esta viene a incluirse en un espacio pautado por esas prácticas previas. La antecede un acumulado de saberes ligados a la experiencia, saberes del hacer, al igual que de competencias y aptitudes personales cultivadas en el mismo oficio (BAYARDO, 2007).

Aquí es importante destacar el documento de la UNESCO, denominado Replantear la educación. ¿Hacia un bien común mundial? (UNESCO, 2015), destaca el papel de la educación como el elemento fundamental de marco mundial integrado de

R. Opin. Jur., Fortaleza, ano 20, n. 33, p.135-164, jan./abr. 2022 
los objetivos de desarrollo sostenible, destaca la necesidad de transformación de la educación adecuándola a los cambios y retos de los contextos actuales, con enfoques que generen una mayor justicia, la equidad social y la solidaridad mundial, considerándola como la herramienta más valiosa de transformación de las sociedades. El mundo en el siglo XXI está obligado a desaprender para reaprender a aprender sobre la relación dialéctica entre naturaleza, la sociedad, la política, y la cultura, ello es uno de los retos de la universidad.

Desde lo psicopedagógico, vale la pena destacar por su pertinencia en el análisis de la Cultura y el Derecho, son refrendados los postulados del enfoque socio-histórico cultural de Vygotsky (1987), al reconocer que las funciones psíquicas superiores son un producto de la apropiación de la experiencia histórico-social y se encuentran en los objetos y fenómenos que, a su vez, constituyen síntesis del decursar histórico de la humanidad; o sea, la apropiación constituye el mecanismo fundamental por el cual se produce el desarrollo psíquico humano.

Según la teoría del autor estudiado, las estructuras formales de la mente se forman como producto de la apropiación del bagaje cultural producido por la evolución histórica de la humanidad que se transmite en la relación educativa; estas se comunican de generación en generación e implican contenidos, conocimientos, junto a formas, estrategias, modelos de conocimiento, que el individuo capta, comprende, asimila y practica; por esto se resalta el valor de la instrucción y se le da gran peso a la actividad tutorada.

Para los autores del artículo, queda claro que la carrera de gestión sociocultural para el desarrollo se compone de un proceso multidisciplinar en su malla curricular, el que persigue en su objetivo formativo la transformación progresiva y sostenible de las problemáticas sociales que se encuentran en contextos diversos de la sociedad de sus problemas sociales, esa es su meta como fin, contextualizar las políticas públicas en el área de la cultura en pos de garantizar los derechos culturales en la nación cubana, como lo refrendan en sus juicios Martínez Casanova (2015), Borges Machín (2018), Puebla Rodríguez (2019), requerido de un cuerpo legal con rango de Ley en su desarrollo normativo en el derecho sustantivo.

Por estas razones, deberá estar contextualizado con la apropiación por parte del Estado de la codificación y jerarquización de los valores y significados de la cultura, asumido como el ente centralizador y unificador de las acciones que le competen a la cultura a través de la creación de instituciones y agentes como servidores públicos por el Ministerio de Cultura.

Resumiendo, en esta transformación que se ejecuta con el nuevo modelo económico y social se implementan una serie de recursos que le aportan los saberes de la cultura, con ellos se genera la participación de los actores comunitarios incidentes en su formación, con un plan diseñado a partir de estrategias diseñadas dentro de las políticas 
La gestión sociocultural para el desarrollo en Cuba y Brasil: un estudio desde el derecho constitucional cultural

públicas del Estado desde el Derecho Constitucional cultural en pos de contextualizar las garantías de los derechos culturales, labor que se ejecuta en los municipios a través de los gestores culturales, tal y como lo mandata el texto constitucional de 2019.

La carrera en estudios socioculturales surge en la nación cubana en el curso 1999. 2000, tuvo un carácter experimental en la Universidad de Cienfuegos, extendiéndose luego en todas las universidades del país como lo dispuso el MES. Los campos de acción fueron concebidos en la gestión y la promoción sociocultural, la teoría y la metodología social, la historia y el pensamiento cultural y la cultura cubana, en pos del desarrollo cultural del país.

Como carrera, la Licenciatura en Estudios Socioculturales, se aprecia cómo está situada en el área de las llamadas humanidades, se planteó desde el inicio como su concepción era de formar un profesional de perfil amplio, que diera respuesta a la pertinencia, calidad y al proceso de internacionalización propio de la educación superior de nuestros tiempos, por ello fue diseñada a partir de la conjunción de varias carreras ya establecidas en el contexto de la enseñanza superior en Cuba. Carreras como Historia, Sociología y otras que se han impartido por varios cursos y de las que existe una vasta experiencia, pero establecidas con perfiles del profesional ya delimitados (MES).

Como continuidad, a partir del curso 2016-2017, por determinación del Consejo Nacional de Carrera del Ministerio de Educación Superior se decide, con vistas a lograr una mejor especialización de este egresado hacia el área de la gestión cultural, se decide modificar el plan de estudios y hacerle un cambio al nombre a la carrera, Licenciatura en Gestión Sociocultural para el Desarrollo, como objeto de análisis en el contexto del artículo.

Otro elemento a destacar, es que el objeto de trabajo del egresado de esta carrera como gestor cultural se centra en los procesos de desarrollo sociocultural que ocurren en diferentes contextos sociales, especialmente aquellos que inciden en el incremento de la calidad de la vida colectiva, el enriquecimiento espiritual, el fortalecimiento de la identidad cultural y la capacidad de participación de la población en dichos procesos (CUBA, 2017). Las vías de ingreso para su estudio han estado centradas en sectores como el de la Industria Turística, la Industria del Azúcar, el sector de la cultura y la educación, como de organismos claves de la economía, ente otras.

\section{LA CULTURA, EL DERECHO CULTURAL Y LOS DERECHOS CULTURALES}

La primera definición científica del concepto de la cultura se aporta por el antropólogo Tylor sostiene desde su postura “(...) cultura es ese todo complejo que comprende conocimientos, creencias, arte, moral, derecho, costumbres y cualesquiera 
otras capacidades y hábitos adquiridos por el hombre en tanto que miembro de una sociedad (...)" (TYLOR, 1871, p. 1).

Para la UNESCO la cultura es:

(...) el conjunto de rasgos distintivos, espirituales y materiales, intelectuales y efectivos que caracterizan una sociedad o un grupo social. Ello engloba, además de las artes y de las letras, los modos de vida, los derechos fundamentales del ser humano, los sistemas de valores las tradiciones y las creencias (...) (UNESCO, 1982, online).

Entonces, ¿qué son los derechos culturales? son parte de la categoría de derechos más emblemática respecto a las divisiones ideológicas en materia de derechos humanos cristalizadas tras la II Guerra Mundial en el siglo pasado por la humanidad. Ha sido el contacto entre las distintas culturas, debido a la globalización y a los constantes movimientos migratorios, que han estado presentes durante toda la historia de la humanidad.

De manera similar, los fundamentos filosófico-jurídicos de la Declaración Universal de los Derechos Humanos desde el Derecho Internacional (1948), se valora que expresan con rigor y profundidad las cuestiones fundamentales acerca de los derechos del hombre y así mismo, enuncian con claridad que se trata de derechos inherentes al ser humano desde el ámbito internacional. Así mismo, este hecho jurídico acontecido en la ciudad de Paris, ocurre después de largas negociaciones entre los países que entonces formaban la Organización de las Naciones Unidas en este momento histórico analizado.

Por la razón antes mencionada, se considera que la Declaración de los Derechos Humanos constituye la corriente clásica y realista del iusnaturalismo. Paradójicamente el siglo XX fue el siglo que vio gestar la Declaración Universal de los Derechos del Hombre (1948). El recorrido histórico del siglo XX, ha resultado un tiempo que ha presenciado, como pocos momentos de la historia humana, al atentar dramática y cruelmente contra la vida y la dignidad del hombre, del que aún en el siglo XXI se padece.

De manera similar, en el artículo 15, del Pacto Internacional de Derechos Económicos, Sociales y Culturales de 1966, señala que los Estados Parte, reconocen el derecho de toda persona a participar en la vida cultural; a gozar de los beneficios del progreso científico y de sus aplicaciones; y a beneficiarse de la protección de los intereses morales y materiales que le correspondan por razón de las producciones científicas, literarias o artísticas de que sea autora.

\footnotetext{
${ }^{2}$ Traducción libre de: "Culture or Civilization, taken in its wide ethnographic sense, is that complex whole which includes knowledge, belief, art, morals, law, custom, and any other capabilities and habits acquired by man as a member of society."
} 
La gestión sociocultural para el desarrollo en Cuba y Brasil: un estudio desde el derecho constitucional cultural

Por lo que, se afirma por los autores del artículo que, la Declaración Universal de los Derechos Humanos proclamada en 1948, así como los Pactos Internacionales de Derechos Económicos, Sociales y Culturales y de Derechos Civiles y Políticos aprobados por la Asamblea de las Naciones Unidas en 1966, constituyen hechos históricos jurídicos de significación en el orden del reconocimiento de derechos fundamentales a todos los hombres, cualquiera fuera el país o el sistema jurídico, o la cultura a la que pertenezca.

Del mismo modo, se justiprecia que la Declaración Universal sobre Diversidad Cultural, adoptada en la Conferencia General de la UNESCO (2001), reconoce que la cultura adquiere formas diversas a través del tiempo y del espacio, y que esa diversidad cultural es patrimonio común de la humanidad. Esta declaración también recuerda que los derechos culturales hacen parte de los derechos humanos, que son universales, indisociables e interdependientes.

En la misma línea de ideas analizadas de la normativa internacional, se valora como la Carta Cultural Iberoamericana adoptada en Montevideo (2006) afirma el valor central de la cultura y la necesidad de promover y proteger la diversidad cultural en el espacio de Iberoamerica.

De hecho, se pondera que el núcleo duro de los derechos humanos, por un lado, están los derechos reconocidos por normas de "ius cogens" y por otro lado los reconocidos a través de normas consuetudinarias regionales establecidas a través de convenios. De aquí que se preconice por los autores del artículo, a partir de la Teoría del Estado y del Derecho por autores consultados como Kelsen (1993), Fernández Bulté (2007), los que han profundizado sobre el Estado, en cuanto a "territorio, cobro de impuestos, y soberanía”, solo faltó a consideración de los articulistas la inclusión de la "cultura" como rasgo, por la pertinencia de la identidad cultural del Estado de Derecho.

Empero, la Constitución como cultura comprende, a juicio de Häberle, no solo las normas dirigidas al entendimiento de los juristas, sino el hecho de cómo penetra la sociedad civil en la propia Constitución y hace suyos sus valores. Lo que a veces lleva a la ampliación de los sujetos de derecho. Hay que resaltar que la voz constitución se utilizaba desde la antigüedad romana y se retomó en la Edad Media (HÄBERLE, 2002).

El análisis realizado por este autor estudiado, para quien, la Constitución Cultural es la consagración de los derechos culturales a nivel normativo, a la vez que a la normativización constitucional de valores, principios y reglas que orientan la acción en ese ámbito específico. Pero necesita de normas jurídicas que la complementen y den las garantías adecuadas a estos derechos culturales por el Estado.

Por esta razones, de aquí que se reconozca por la academia al "Derecho Cultural" como una disciplina académica nueva, en desarrollo y evolución, en la misma se agrupan temáticas de diversas normas jurídicas, las que regulan las actividades relativas a la educación, la universidad, las ciencias y las tecnologías, los derechos de autor, el

R. Opin. Jur., Fortaleza, ano 20, n. 33, p.135-164, jan./abr. 2022 
patrimonio cultural, la promoción cultural y de las artes, los medios de infocomunicación, el derecho indígena, la promoción de las culturas populares y los símbolos nacionales, de aquí su transdisciplinariedad. Los que a consideración de los articulistas integran los derechos a la educación, el laicismo, la libertad académica, la enseñanza religiosa, la alfabetización, el magisterio, los grupos sociales que interactúan, la educación especial, los medios de comunicación, entre otros.

En esta misma cuerda, a juicio de Pérez Luño, quien valora que la segunda generación corresponde a los derechos económicos, sociales y culturales, concretamente los derechos de participación, participación en las prestaciones y servicios públicos. los derechos culturales son derechos humanos complejos, y no solo están presentes en la última generación de derechos, o derechos de solidaridad, sino que están presentes en todas las generaciones de derechos (PÉREZ LUÑO, 2004).

Su fundamento jurídico a consideración de los autores del artículo, se sustenta en que, los derechos culturales como derechos humanos, al promoverse entre las personas el respeto a la diversidad de ser, de pensar, de actuar, de desarrollarse, de proyectar un futuro y de defender un pasado histórico; comienzan a verse en el ámbito internacional como un mecanismo eficaz no sólo de reconocimiento y protección de los derechos fundamentales, sino también para lograr la cohesión social y la paz en el mundo, aspectos estos no logrados de manera adecuada aún en todas las naciones al no ser debidamente garantizados en su plenitud por los Estados en sus ordenamientos jurídicos en normas orgánicas, por lo que aún queda mucho por trabajar al legislador en el derecho sustantivo.

Como materia jurídica se aprecia cómo se ha extendido en algunas de las escuelas de Derecho, es el caso de la francesa, donde se ha desarrollado el "Derecho de la Cultura”, sus ejes temáticos son el derecho patrimonial de la cultura, el derecho de la creación y la formación cultural, el patrocinio cultural, la propiedad literaria y artística. En Iberoamérica, como referente cultural ya citado, se constata como España, en la Constitución de 1978 adquieren los derechos relacionados con la educación o con la libertad de creación artística, ambos derechos considerados culturales.

En la nación colombiana, se regula en una Ley de la Cultura desde 1997; Chile, acoge los derechos culturales a partir de una Ley Orgánica No. 21.045 de 2017. En Venezuela, se reconoce a través de la Ley Orgánica de la Cultura, en el Decreto 1.411 de 2014. En Ecuador, se norma en la Ley Orgánica de la Cultura en 2016. En Bolivia, se dispone a través de la Ley de Patrimonio Cultural Boliviano en el 2014.

Por ello, el derecho a participar en la vida cultural de una nación es requerido como la pieza clave del catálogo de los derechos culturales, tal y como lo aportan en sus estudios Ruiz Miguel (2003), Montero Moya (2004), Maraña (2010), García Cívico (2018), Pegoraro (2019). 
La gestión sociocultural para el desarrollo en Cuba y Brasil: un estudio desde el derecho constitucional cultural

En México, en la formación de los juristas desde la academia, como nueva disciplina jurídica, se encuentra en proceso de sistematización los contenidos de los derechos culturales, sobre la competencia del Estado en la materia cultural y artística, el estudio de la Ley de la Cultura, del patrimonio cultural, los tratados internacionales y de la jurisprudencia. De aquí que se independizara del Derecho Administrativo (CACHO PÉREZ, 2017).

Por su turno, en Brasil, con la aprobación de la Constitución de la República brasileña de 1988, se puede decir que hubo un gran avance, no que surgiera directamente de años de cultura concreta y tutela legal. Como es una Constitución que suele proteger a los lineamientos fundamentales y a la dignidad de la persona humana, es indispensable establecer maneras efectivas para llegar o desarrollar el país y proteger el ejercicio de la ciudadanía. A principio, no hay forma de lograr estos objetivos para tutelar la cultura brasileña, sea en el aspecto material e inmaterial. Sin embargo, también se puede trabajar el tema utilizando la sostenibilidad, que permea "todas y cada una de las actividades, con el objetivo de permitir un mayor equilibrio ambiental, social, económico y ético, que en conjunto permitan el desarrollo de la dimensión jurídico política" (GOMES; FERREIRA, 2018, p. 160, nuestra traducción ${ }^{3}$ ).

En el texto constitucional brasileño, el art. 215 establece la garantía del pleno ejercicio de los derechos culturales, así como determina la obligación del Estado de fomentar la apreciación y difusión de las manifestaciones culturales. Así, se instituyeron principios que deben ser utilizados como base para la legislación no constitucional, así como para los actos de gobierno, por medio de la creación de políticas públicas.

Con relación a las políticas públicas, se puede mencionar el Programa Nacional de Arte, Cultura y Ciudadanía, instituido por medio de la Ordenanza no 156/2004, un proyecto de gran valor para la población brasileña. La Ordenanza prevé dicho programa como una forma de "promover el acceso a los medios de disfrute, producción y difusión cultural, así como potenciar las energías sociales y culturales, con el objetivo de construir nuevos valores de cooperación y solidaridad” (BRASIL, 2004, online). Lo más interesante del programa es que, como afirman Rocha y Aragão, la población brasileña es, en cierto modo, responsable de garantizar el desarrollo de un derecho que ellos mismos disfrutarán. Se explica:

Se pone de relievo que el público asistido es el verdadero ejecutor de las acciones, es decir, no es el gobierno el que realiza las actividades, sino que ellos, en base a las condiciones que marca el Estado, son los encargados de plantear sus propias propuestas. Cultura Viva, por lo tanto, es una política de

\footnotetext{
${ }^{3}$ Traducción libre de: "toda e qualquer atividade, com o objetivo de permitir maior equilibrio ambiental, social, econômico e ético, que juntos permitirão o desenvolvimento da dimensão jurídico-política" (GOMES; FERREIRA, 2018, p. 160).
}

146 - R. Opin. Jur., Fortaleza, ano 20, n. 33, p.135-164, jan./abr. 2022 
reconocimiento que incentiva la producción cultural de los colectivos que participan en ella (ROCHA; ARAGÃO, 2011, p. 8, nuestra traducción ${ }^{4}$ ).

Además, se coloca de manifiesto que la educación de calidad es esencial para que la población brasileña, como sujeto de derechos, sea consciente de que los Derechos Culturales están previstos como un derecho constitucionalmente garantizado y para que pueda tomar las medidas necesarias para hacerlos efectivos. "Así, el derecho fundamental a la educación de calidad debe ser ofrecido por el Estado, a fin de permitir un mayor acceso a la participación social de los académicos que proponen, a través de nuevas ideas y soluciones, una nueva reformulación del ser, del pensar y del actuar en el contexto social" (GOMES; FERREIRA, 2017, p. 99, nuestra traducción ${ }^{5}$ ).

Se puede concluir que en el Estado Democrático de Derecho brasileño, el Derecho Cultural pasó a ser considerado como un verdadero derecho autónomo y, por lo tanto, se produjo un notable aumento de su importancia frente al ordenamiento jurídico brasileño en general.

Estos elementos sistematizados permiten a los autores del artículo justipreciar que los Derechos Culturales, son el resultado del continuo desarrollo que han tenido las Constituciones de los Estados y cómo los mismos han asimilado los instrumentos y documentos internacionales en sus ordenamientos jurídicos, a partir de su texto constitucional. La cuestión pervive en cómo se contextualizan las garantías de estos derechos en los Estados. Toda vez que el Estado de Derecho tiene que garantizar el acceso a la cultura, el disfrute de los bienes y servicios que presta el Estado en materia de derechos, y por último el ejercicio de estos derechos, los que debe ser regulados en sus ordenamientos jurídicos en cuerpos jurídicos especiales para disfrutar de las garantías de los derechos culturales.

Lo válida el quehacer del Grupo de Friburgo, para la creación del concepto y el contenido de los derechos culturales. El mismo ha elaborado un listado de los derechos culturales basándose en distintos instrumentos normativos dispersos, cuyo reflejo se encuentra en la Declaración de Derechos Culturales (2007). Los que hay que incorporar en la formación de la cultura jurídica.

Destacar en este sentido, concomitante con las ideas valoradas up supra, que los proyectos socioculturales sin la presencia del paradigma humanista que desde el siglo XX, quien como Vygotsky (1896-1934) propuso en su enfoque histórico-cultural, donde

\footnotetext{
${ }^{4}$ Traducción libre de: "Destaca-se que o público assistido é o próprio executor das ações, ou seja, não é o governo quem realiza atividades, mas estes, a partir das condições colocadas pelo Estado, são responsáveis por implementar suas próprias propostas. O Cultura Viva, portanto, é uma política de reconhecimento que estimula a produção cultural dos grupos que dele participam" (ROCHA; ARAGÃO, 2011, p. 8).

${ }^{5}$ Traducción libre de: "Assim, o direito fundamental à educação de qualidade precisa ser devidamente fornecido pelo Estado, de modo a prestigiar maior acesso à participação social dos estudiosos que propõem, mediante novas ideias e soluções, uma nova reformulação do ser, do pensar e do agir no contexto social" (GOMES; FERREIRA, 2017, p. 99).
} 
La gestión sociocultural para el desarrollo en Cuba y Brasil: un estudio desde el derecho constitucional cultural

destacaba el carácter interdisciplinario, humanista y dinámico de los procesos cognitivo socializadores y donde se reconoce la importancia que para estos procesos entrañaban los contextos, la propia formación del sujeto y su interrelación e implicación en las transformaciones sociales y culturales. Cuestión a la que los autores del artículo la consideran adecuada, es lo que ejecuta el graduado en gestión sociocultural para el desarrollo desde su modo de actuación, a través de la formación docente desde la integración de los contenidos (ÁLVAREZ DE ZAYAS, 2004).

Hay que resaltar, que, durante mucho tiempo, por parte de los aportes de sociólogos, antropólogos, investigadores, filósofos, escritores, y de otras profesiones, la han entendido de diversas formas y con diferentes significados. En contexto, se analiza que la cultura es concebida como la carga de la vieja sabiduría (o falta de) que los hombres del presente reciben de sus antepasados y heredan a sus descendientes, con el retoque de la mínima aportación o cambio que las mujeres y hombres de hoy dan a esa cultura general.

Por ello, se asevera por los autores del artículo que, al reconocer el fenómeno jurídico como un fenómeno cultural, se requiere contextualizar y robustecer al orden jurídico en el ámbito político, social e histórico en los ordenamientos jurídicos por el órgano legislativo. El Derecho como fenómeno dinámico, su estudio debe revisarse continuamente para que sea adecuado a la cultura política dentro de la que se encuentra inmerso, de aquí la necesidad de la formación desde la academia para potenciar la identidad cultural de una nación.

No cabe dudar que, la cultura es un producto de la organización social, como traducción de la exigencia de una comunidad, que perdura en el tiempo a través de la transmisión de sus elementos constitutivos: principios, conocimientos, instituciones, costumbres y actitudes, integrados y sistematizados de manera permanente a través del proceso educacional y casi insensible de los eslabones sociales en sus diferentes niveles de amalgamamiento. Los dos logros a destacar a la organización internacional de la UNESCO vinculados al objetivo que se persigue en el artículo, son la Declaración Universal sobre la Diversidad Cultural (2005) y la Convención sobre la Diversidad de las Expresiones Culturales (2005).

Aunque de manera somera, se precisa que este concepto ha variado, lo ha hecho con lo que se conoce hoy como Sociedad de la Información, donde con el uso de las tecnologías informáticas en la web 2.0, se afectó la coexistencia de diversas culturas, al no poderse delimitar las fronteras entre los Estados, potenciado con la tecnología que en cada momento están evolucionando (5G) conocida como "cultura digital" al mutar los patrones tradicionales, donde pervive la diversidad cultural en un entorno digital. Quien en el siglo XXI se negaría a reconocer que existe la cooperación cultural entre los Estados, que hay una industria cultural como distribuidora de bienes y servicios culturales potenciada a través de las Tecnologías de la Informática y las Comunicaciones

R. Opin. Jur., Fortaleza, ano 20, n. 33, p.135-164, jan./abr. 2022 
(TIC), lo que esta conducida por las naciones que mayores riquezas tienen, eso es otra de las realidades del siglo XXI. Y en los más pobres contextualizado a través de la economía colaborativa a través del trabajo 3.0.

En consecuencia, a partir de los análisis anteriores realizados, en el artículo son valorados los aportes de autores cubanos sobre la cultura, que no son todos, en ello la postura de Martí (1973), quien afirmó “(...) dígase hombre y se han dicho todos los derechos. Señaló también que el derecho aplicado sin cultura se parece el crimen (...)” (MARTÍ, 1973, p. 289).

O cuando Castro, se dirigió a los intelectuales cubanos en su discurso "Palabra a los intelectuales" en 1961, al señalar sobre el concepto de cultura señaló que rebasa el ámbito de las artes y las letras. Se remite a los valores y las demandas de vida espiritual que atraviesan al conjunto de la sociedad. La cultura tenía que ser lo primero en ser salvado.

Por otra parte, está el juicio de Rodríguez, quien, en el artículo, "los comunistas ante el proceso y las perspectivas de la cultura cubana”, en su libro Letra con Filo, permite obtener una concepción exacta de lo que significan cultura, nacionalidad y cubanía, y más aún, la interrelación entre estos conceptos (RODRÍGUEZ, 1987).

Otra postura a considerar en este estudio es la de Hart Dávalos, quien señaló desde sus estudios al dirigir durante muchos años el Ministerio de Cultura, al "estudiar los factores que determinaron el distanciamiento que se produjo entre cultura y política es el primer deber de quienes, en el siglo XXI, se propongan luchar por la redención del hombre, único camino para salvar a la civilización del colapso que la amenaza. De ahí la importancia estratégica de desarrollar masivamente una cultura general integral que a los cubanos nos viene de la mejor tradición nacional. (...) El principal obstáculo que se levanta ante esta noble aspiración radica en que debe lograrse sobre el presupuesto ético de la lucha por la justicia y la solidaridad humana (...)" (HART DÁVALOS, 2001, p. $60)$.

El autor estudiado valoró que, la relación hombre-naturaleza-universo, tal y como ha sido concebida por el pensamiento pedagógico cubano de los siglos XX y XXI han incidido en la integralidad de la cultura en la nación cubana.

Se destaca como en Cuba, desde el 1938, la labor en la preservación del patrimonio cultural por Roig desde la Oficina del Historiador de la Ciudad de la Habana, entidad con un carácter autónomo y con la responsabilidad de fomentar la cultura cubana en la conservación de La Habana como patrimonio. Continuada por la labor de Leal hasta el siglo XXI con su muerte, son hechos que identifican como el Estado cubano apuesta por el fomento de la cultura nacional.

En consecuencia, se arguye que el Derecho, al estar concebido como una manifestación de la Cultura, entendiéndose ésta como la aportación inteligente y razonada a la humanidad por la humanidad. Desde la mínima creación artesanal, 
La gestión sociocultural para el desarrollo en Cuba y Brasil: un estudio desde el derecho constitucional cultural

pasando por el profundo conocimiento de la estructura y destrucción del átomo, hasta la naturaleza, origen y evolución del universo, usos, costumbres, música, folklor, literatura, etc. conforman eso llamado cultura. Cada contribución de la razón humana al conocimiento y su utilización por los propios hombres es cultura. Cada obra de arte, libro, poema, tradición, rito y ceremonia religiosa o sistema educativo, expresan la concatenación entre pasado, presente y futuro de una comunidad, es su identidad colectiva de una nación determinada, y en el caso de Cuba debe ser potenciada en la gestión turística que se fomenta por parte del Ministerio de Turismo, tributando al desarrollo local del municipio en lo endógeno y en lo exógeno.

En este sentido, a consideración de los articulistas, son analizados los aportes desde las ciencias jurídicas sobre la cultura. Para ello, Freund, asume el Derecho no solo se ejerce a través de la coacción física, sino también mediante la dominación ideológica o espiritual de los medios de información o de cultura (FREUND, 1968).

El Derecho es concebido como un conjunto de normas que rigen la conducta externa de los hombres en sociedad y estas normas, junto con otros cuerpos normativos y otros factores e instituciones sociales constituyen la cultura, como lo señaló Kant en sus aportes desde la teoría (KANT, 1994).

Teniendo en cuenta que, la protección de la diversidad cultural es uno de los desafíos de las sociedades modernas en el mundo en el que vivimos, globalizado, donde la protección de las innumerables culturas es uno de los retos de la política internacional de hoy en día. Tal y como lo considera De Luca, al señalar que tienen un argumento parecido al anterior, ya que defienden que los derechos humanos son la única ética universal posible en un mundo multicultural (DE LUCA, 1997).

En esta misma línea, la constitución cultural, para Ruiz Robledo, es el conjunto de normas destinadas a proporcionar el marco jurídico fundamental para la estructura y el funcionamiento de la vida cultural de una nación (RUIZ ROBLEDO, 1998). Häberle señala en sus aportes que, la Constitución como fenómeno cultural viene aparejada de una complejidad marcada por el necesario acercamiento a los orígenes históricosculturales y a las condiciones sociales contemporáneas de una nación (HÄBERLE, 2002).

Para Pérez Gallardo, refiere que, la cultura también es política y las políticas culturales son herramientas que posibilitan un proceso de retroalimentación e implican un proceso de aprendizaje intergeneracional, es decir, sustentable (PÉREZ GALLARDO, 2011).

Otra posición es la de Cándano Pérez y Moreno Cruz, quienes sostienen desde su argumento que, desde el punto de vista cultural, los derechos intelectuales se encargan de permitir, fomentar y proteger dichas manifestaciones dentro de una comunidad, por lo que el reconocimiento constitucional de los derechos derivados de la creación intelectual evidencia el reconocimiento de un conjunto de derechos y facultades

R. Opin. Jur., Fortaleza, ano 20, n. 33, p.135-164, jan./abr. 2022 
otorgado a los creadores y a los inventores para así garantizar, entre otros efectos, la salvaguarda del interés público para el desarrollo científico-tecnológico y socioeconómico (CÁNDANO PÉREZ; MORENO CRUZ, 2019).

Para mejor ilustración luego de lo analizado por los estudiosos, son acotados algunos ejemplos de ejes temáticos que demuestran el nexo integrador de la Cultura y el Derecho, que permitan a la academia desarrollarlo en estudios en las carreras de Gestión sociocultural y en la de Derecho para el desarrollo académico:

- Las tradiciones culturales y la costumbre social del Estado de Derecho

- El derecho como obra cultural establecido en códigos, leyes, tratados (ejemplos: Código de Hamurabi, los mandamientos de Moisés, la Ley de las Doce Tablas)

- La cultura cívica de los ciudadanos fomentada en los diferentes niveles de estudios

- Las normas tributarias vinculadas a la cultura en todas sus manifestaciones a cumplir por los actores que participan del sector privado y estatal

- La norma civil, administrativa, y penal vinculada a la cultura en todas sus manifestaciones

- El Derecho y la historia desde la visión cultural

- El Derecho y la religión

- El Derecho de Autor y de la propiedad intelectual en la creación cultural

- El Derecho de contratos en la negociación de las obras culturales

- El Derecho Laboral en la gestión cultural de los ciudadanos

- El Derecho Urbanístico vinculado al Patrimonio cultural de la nación

\subsection{RECONOCIMIENTO DE LA CULTURA COMO DERECHO CONSTITUCIONAL EN EL ESTADO DE DERECHO EN CUBA}

Es un hecho jurídico que, la Constitución es el núcleo duro en la relación entre el Derecho y la Cultura. Ello se asevera porque la Constitución constituye la expresión situada y concreta de la cultura y, como tal, responde a las condiciones históricas específicas donde esta opera. En la misma, como norma suprema se regulan los procederes para la gestión del capital cultural desde la aspiración humanista de un deber ser, supeditado al bienestar colectivo, desarrollada en leyes orgánicas en el ordenamiento jurídico.

Hay que destacar con la afirmación anterior que, la Constitución cubana aprobada en el 2019, en la actualización del modelo económico y social, reconoce e incorpora el elemento cultural como uno de los fundamentos del texto normativo, con ello es renovadora con respecto a las constituciones precedentes en nuestra nación desde el triunfo de la revolución en 1959, como es el caso de la de Constitución de 1976.

Como se aprecia, los avances del texto constitucional aprobada en el 2019, se conciben en el Título III: "Fundamentos de la política educacional, científica y cultura". 
La gestión sociocultural para el desarrollo en Cuba y Brasil: un estudio desde el derecho constitucional cultural

Visto desde su dimensión jurídica, se justiprecia como representa un instrumento normativo de poder de la clase gobernante para el ejercicio de la autoridad política. Garantiza la legitimación necesaria para el dictado de las políticas públicas de manera robusta. Es el ejercicio del poder político en pos de lograr un mandato. Se expresa este mandato en los artículos:

Articulo 13 - El Estado tiene como fines esenciales: promueve el desarrollo sostenible que asegure la prosperidad individual y colectiva; proteger el patrimonio natural, histórico y cultural de la nación; y asegurar el desarrollo educacional, científico, técnico y cultural del país.

Artículo 32 - El Estado orienta, fomenta y promueve la cultura en todas sus manifestaciones. De igual modo, se promueve la libertad de creación artística en todas sus formas de expresión, conforme a los principios humanistas en que se sustenta la política cultural del Estado y los valores de la sociedad socialista;

i) se fomenta y desarrolla la educación artística y literaria, la vocación para la creación, el cultivo del arte y la capacidad para apreciarlo;

j) defiende la identidad y la cultura cubana y salvaguarda la riqueza artística, patrimonial e histórica de la nación y;

k) la protección de los monumentos y los lugares notables por su belleza natural o reconocimiento artístico e histórico.

Artículo 43 - La mujer y el hombre tienen iguales derechos y responsabilidades en lo económico, político, cultural, laboral, social, familiar y en cualquier otro ámbito. El Estado garantiza que se ofrezcan a ambos las mismas oportunidades y posibilidades.

Artículo 46 - Todas las personas tienen derecho a la vida, la integridad física y moral, la libertad, la justicia, la seguridad, la paz, la salud, la educación, la cultura, la recreación, el deporte y a su desarrollo integral.

Artículo 54 - El Estado reconoce, respeta y garantiza a las personas la libertad de pensamiento, conciencia y expresión. La objeción de conciencia no puede invocarse con el propósito de evadir el cumplimiento de la ley o impedir a otro su cumplimiento o el ejercicio de sus derechos.

Artículo 57 - Toda persona tiene derecho a profesar o no creencias religiosas, a cambiarlas y a practicar la religión de su preferencia, con el debido respeto a las demás y de conformidad con la ley.

Artículo 75 - Todas las personas tienen derecho a disfrutar de un medio ambiente sano y equilibrado. El estado protege el medio ambiente y los recursos naturales del país. Reconoce su estrecha vinculación con el desarrollo sostenible de la economía y la sociedad para hacer más racional la vida humana y asegurar la supervivencia, el bienestar y la seguridad de las generaciones actuales y futuras.

Artículo 79 - Todas las personas tienen derecho a participar en la vida cultural y artística de la nación. El Estado promueve la cultura y las distintas manifestaciones artísticas, de conformidad con la política cultural y la ley (CUBA, 2019, online).

Es pertinente clarificar que, el organismo de la Administración Pública cubana que dirige la cultura y sus políticas públicas es el Ministerio de Cultura desde la década de los 70' del siglo $\mathrm{XX}$, con representaciones administrativas en todo el territorio 
nacional a través de direcciones provinciales y municipales. Le corresponde este mandato administrativo de conjunto con los órganos de gobierno a nivel provincial y municipal contextualizar y garantizar estos derechos de la ciudadanía de las políticas culturales, en respuesta al artículo 32 constitucional. Pero, hay que destacar que no se ha promovido por el legislador una Ley orgánica de la Cultura en el derecho sustantivo.

Si bien es cierto que, el sector estatal en Cuba es quien lleva la delantera en la organización y ejecución de estas políticas públicas en materia de cultura, también hay que reconocer que le brinda la posibilidad de que intervengan sectores sociales no gubernamentales, con ello se permite una visión integral del fenómeno cultural en sí y que el acceso a la cultura como derecho fundamental, visto desde una posición aglutinadora y sus derechos derivados, sea más efectivo en su aplicabilidad, así como que su alcance llegue a todos los extractos sociales, de modo que se logre una mayor democratización de la cultura (SARDA; LLOGA, 2020). Que como se valoraba, se requiere de una Ley de Cultura, lo que no quiere de algún modo decir que estos derechos no puedan reclamarse, la Constitución de 2019, permite al ciudadano reclamar estos derechos en sede judicial establecidos en el artículo 40 y el 45 en cumplimiento del principio de legalidad.

Por lo que afirma por los autores del artículo que, luego del estudio de estas diversas posturas, que en el ordenamiento jurídico cubano hay presencia del Derecho Cultural a través de cuerpos normativos, a partir de:

- Ley No. 1. Ley de Protección del Patrimonio Cultural, de 1977.

- Ley No. 2. Ley de los Monumentos Nacionales y Locales, de 1977.

- Ley No 14, Ley de Derecho de Autor de 1979.

- Ley No. 59, Código Civil de 1987.

- Ley No. 81, del Medio Ambiente de 1997.

- Ley No. 106, Del Sistema Nacional de Museos, de 2009.

- Ley No. 113, Del Sistema Tributario de 2013.

- Ley No. 116, Código del Trabajo de 2016.

- Normas jurídicas relacionadas con el ordenamiento urbanístico y la planificación física, vinculadas al Derecho Patrimonial.

- Decreto Ley No. 373. Del Creador Audiovisual y Cinematográfico Independiente de 2019.

- Decreto Ley No. 370. Sobre la informatización de la sociedad en Cuba de 2019.

- Decreto Ley No. 41. Instituto de Información y Comunicación Social de 2021.

Es importante destacar que no todo está resuelto en materia normativa, perviven insuficiencias que en el ordenamiento jurídico cubano, a partir de que no existe una Ley de la Cultura donde se señale las garantías de los derechos culturales, como lo mandata el artículo 79 constitucional; que permitan a consideración de los autores el cauce adecuado de cumplir las políticas públicas, que promueva y proteja el ejercicio de los 
La gestión sociocultural para el desarrollo en Cuba y Brasil: un estudio desde el derecho constitucional cultural

derechos culturales y establezca las bases de coordinación para el acceso de los bienes y servicios que presta el Estado en materia cultural, sus mecanismos para ejercitarlos, la responsabilidad de los servidores públicos, la divulgación de la identidad cultural cubana, entre otras cuestiones por legislar; hoy expandidas de manera exponencial con las herramientas de las Tecnologías de la Informática y las Comunicaciones en la web 2.0 y en la denominada economía colaborativa por parte de los actores económicos que se dedican a la creación artística.

Cuestión esta que guarda relación con la reciente creación de la creación del Instituto de Información y Comunicación Social (IICS), el que constituye un cambio cultural en espectro del país. Toda vez que incidirá en una mayor cultura comunicacional, esta será más robusta, como se viene irradiando cultura a través de los 42 canales de televisión, y de las 74 emisoras, las que son internacionales, pues tienen una página web en la internet.

Concomitante con la necesidad de que se promulgue una Ley de Educación, que contribuirán a consideración de los articulistas a reforzar este derecho de segunda generación analizado en el objetivo del artículo. Incidentes en la formación de la cultura jurídica como mandato constitucional a la academia como parte de la educación cívica en los diversos niveles de enseñanza a partir de la general hasta el nivel superior, como se ha señalado desde la integración de contenidos.

También tributan dentro del entramado de la Sociedad Civil cubana, en la formación del Derecho Cultural instituciones como la Unión Nacional de Escritores y Artistas de Cuba (UNEAC) y la Asociación Hermanos Saiz (AHS) al desarrollo de las políticas públicas que se establece por el Estado cubano en la materia cultural. Y afín con la cultura, está la labor de la Unión de Periodistas y Escritores de Cuba (UPEC) en su difusión. Son organizaciones dentro de la sociedad civil que aglutinan a intelectuales, que en muchos espacios son gestores culturales al frente de proyectos comunitarios al tributar al desarrollo local con la economía solidaria.

\subsection{LA FORMACIÓN DE LA CULTURA JURÍDICA EN LA CARRERA DE GESTIÓN SOCIOCULTURAL PARA EL DESARROLLO DESDE EL DERECHO CONSTITUCIONAL CULTURAL}

Los elementos hasta aquí analizados, permiten a los autores del artículo, hacer la propuesta a la carrera en conformar una asignatura como materia optativa en temas básicos distribuidos en bloques, que permitan la integración de contenidos desde la Cultura y el Derecho, y desde el Derecho a la Cultura, al estudiante de la carrera de gestión sociocultural para el desarrollo, con la denominación "Derecho Cultural" donde se impartan los contenidos: 
Bloque 1: La Constitución cultural en Cuba desde el prisma del Derecho Constitucional. Los instrumentos jurídicos que reconocen la cultura como derecho humano desde el Derecho Internacional. Labor de la UNESCO en el desarrollo de la cultura de los Estados. Labor del Instituto de Información y Comunicación para el desarrollo de la política cultural dentro del entramado de la Administración Pública.

Bloque 2: La Cultura, las políticas públicas y las tradiciones culturales en Cuba vistas desde el Derecho por el Ministerio de Cultura. Las garantías de los derechos culturales en el ordenamiento jurídico cubano. La soberanía cultural en Cuba. Los derechos culturales de las personas extranjeras. Las formas asociativas dentro la sociedad civil cubana en el sector de la Cultura (UNEAC, AHS). Labor de los museos, archivos, bibliotecas; el patrimonio cultural y espacios públicos para fomentar el arte y la creación cultural.

Bloque 3: La Cultura y el ordenamiento jurídico cubano: El Derecho de Autor. La Propiedad Intelectual. Derecho Urbanístico. Derecho Ambiental. Derecho Administrativo. La Política Tributaria. El Derecho Contractual. La normativa del creador audiovisual y de los comunicadores. El entorno digital. El cine jurídico. La educación cultural. Las instituciones culturales públicas y las gestionadas por el sector privado. La actividad registral en el sector cultural. Las redes sociales y la cultura cubana.

Bloque 4: El emprendimiento cultural en Cuba desde las regulaciones del Ministerio de Trabajo y Seguridad Social. La cultura y el empresario privado. Un análisis desde el Derecho Laboral y el Derecho Mercantil. La industria cultural en la nación cubana promovida por el Ministerio de Cultura. El turismo cultural desde el prisma del Ministerio de Turismo. Los delitos relacionados con la cultura en Cuba previstos en el Código Penal. La Responsabilidad Administrativa de los actores económicos que intervienen el sector de la cultura. Los proyectos socioculturales comunitarios, sus modos de gestión en los territorios para el desarrollo local.

Lo abordado en relación con el objetivo planteado, permitirá dar cumplimiento a la máxima de la educación en la nación cubana, para tributar a la formación integral de los profesionales desde sus modos de actuación con competencias. Diversas investigaciones, desde sus propuestas teóricas y la aplicabilidad en los procesos de formación con un enfoque integral, desde los juicios estudiados de Tünnerman Bernheim, quienes ponderan su esencia humana y cultural transformadora de la sociedad desde la gestión cultural para fomentar la identidad nacional, contextualizado a través de los proyectos comunitarios a través de ferias de libros, talleres, manifestaciones culturales a través de obras de teatro, circenses, difusión de audiovisuales, entre otras acciones culturales (TÜNNERMAN BERNHEIM, 2009).

Todos estos elementos afrontados en el cuerpo del artículo, luego de la sistematización realizada, permiten argumentar a los articulistas la necesidad de en cumplimiento del objetivo trazado, demostrar la pertinencia de la impartición de los 
La gestión sociocultural para el desarrollo en Cuba y Brasil: un estudio desde el derecho constitucional cultural

contenidos de la materia optativa "Derecho Cultural", por su carácter intertransdisciplinar por profesores de la carrera de Derecho y de Gestión Sociocultural para el Desarrollo, la que por su pertinencia puede implementarse tanto en la formación del gestor cultural para el desarrollo como en la del operador del derecho en la Universidad de Granma, y su extensión a las carreras de humanidades en las ciencias pedagógicas del MES, que permita conocer los horizontes de las garantías constitucionales de los derechos culturales, del que queda mucho por hacer en su construcción con el ciudadano.

\section{CONCLUSIONES}

Los fundamentos filosóficos jurídicos de la Declaración Universal de los Derechos Humanos desde el Derecho Internacional, expresan con rigor y profundidad las cuestiones fundamentales acerca de los derechos del hombre, enuncia con claridad que se trata de derechos inherentes al ser humano desde el ámbito internacional. El cual en el Estado de Derecho se establece a través de la Constitución dentro del núcleo duro en la relación entre el Derecho y la Cultura. Porque la Constitución constituye la expresión situada y concreta de la cultura y, como tal, responde a las condiciones históricas específicas donde esta opera, desarrollados en los ordenamientos jurídicos.

El "Derecho Cultural" como una disciplina académica, agrupa temáticas de diversas normas jurídicas, las que regulan las actividades relativas a la educación, la universidad, las ciencias y las tecnologías, los derechos de autor, el patrimonio cultural, la promoción cultural y de las artes, los medios de comunicación, el derecho indígena, la promoción de las culturas populares y los símbolos nacionales. Integran los derechos a la educación, el laicismo, la libertad académica, la enseñanza religiosa, alfabetización, magisterio, grupos sociales, educación especial, medios de comunicación por su transversalidad.

Es necesaria una actualización de los contenidos que se imparten en la asignatura, a raíz de la implementación de un nuevo Plan de Estudios "E" que contextualice el proceso de actualización del ordenamiento jurídico cubano en la carrera de Gestión Sociocultural para el Desarrollo, al demostrar la pertinencia de la impartición de los contenidos de la materia optativa "Derecho Cultural", por su carácter interdisciplinar por profesores de la carrera de Derecho y de Gestión Sociocultural para el Desarrollo, la que por su oportunidad puede implementarse en ambas carrera en la Universidad de Granma, y su extensión a las carreras sociales y de humanidades.

\section{REFERENCIAS}

AGUIRRE, Severo. Lecciones de historia de Cuba. Cuba: Instituto Superior de Educación, 1961. 
ALBALADEJO, Manuel. Derecho Civil. Introducción y derechos de la persona. España: Bosch, 2002.

ALEXY, Robert. Teoría de los derechos fundamentales. España: Centro de Estudios Constitucionales, 1993.

ALMANZAN OLMO, Sonia. Cultura cubana siglo XX. La Habana: Félix Varel, 2004.

ALMANZAN OLMO, Sonia. Panorama de la cultura cubana. Antología. Cuba: Félix Varela, 2006.

ÁLVAREZ BEROVIDES, Vicente (org.). Los estudios de las políticas culturales. Cienfuegos: Universo Sur, 2016.

ÁLVAREZ DE ZAYAS, Carlos. Interdisciplinariedad: una aproximación desde la enseñanza-aprendizaje de las ciencias. Cuba: Pueblo y Educación, 2004.

ÁLVAREZ DE ZAYAS, Carlos. El Diseño Curricular. Cuba: Félix Varela, 2002.

ARIÑO, Antonio. Sociología de la cultura: la constitución simbólica de la sociedad. España: Ariel, 1997.

ARJONA PEREZ, Martha. Patrimonio cultural e identidad nacional. Cuba: Letras Cubanas, 1986.

ARROYO YÁNEZ, Luis. Los derechos culturales como derechos en desarrollo: una aproximación. Multidisciplinar para la modernización de la Administración Pública. España. 2017.

ATIENZA, Manuel. El derecho como argumentación. España: Ariel, 2006.

ATIENZA, Manuel. Interpretación constitucional. Bogotá: Universidad Libre de Colombia, 2010.

ÁVILA ORTIZ, Raúl. Derecho Constitucional Cultural Iberoamericano. México: UNAM, 2002.

AYES, Gilberto. La Habana: maravilla patrimonial. Cuba: Científico-Técnica, 2017.

BALAGUER CALLEJÓN, Francisco (org.). Derecho Constitucional y Cultura: estudios en homenaje a Peter Häberle. Madrid, 2004.

BARREIRO CARRIL, Beatriz. La diversidad cultural en el Derecho Internacional: La Convención de la UNESC. España: Iustel. 2011.

BASAIL RODRÍGUEZ, Alain (org.). Antropología Social. Selección de lecturas. Cuba: Félix Varela, 2005.

BASAIL RODRÍGUEZ, Alain. Sociología de la cultura. Cuba: Félix Varela, 2004.

BAYARDO, Rubens. Cultura, artes y gestión. La profesionalización de la gestión cultural. Cepi, 2007. Disponible en: www.cepi.us/posgrado/download.php?file=RBayardo.pdf. Acceso en: 22 set. 2021. 
La gestión sociocultural para el desarrollo en Cuba y Brasil: un estudio desde el derecho constitucional cultural

BOBBIO, Norberto. Teoría del ordenamiento jurídico. Brasil: Universidad de Brasilia, 1995.

BOBBIO, Norberto. El tiempo de los derechos. España: Sisterna, 1991.

BORGES MACHÍN, Anaiky Yanelín. Diferencias y relaciones entre Gestión Cultural y Gestión Sociocultural. Gestión Cultural, España, n. 13, 2018.

BORGES MACHÍN, Anaiky Yanelín. Hacia una definición de la gestión sociocultural. Gestión Sociocultural I y II. Cuba: Félix Varela, 2018.

BORGES MACHÍN, Anaiky Yanelín; ZURBANO COBAS, Lilian; CASTRO ACEVEDO, Georgina. Gestión sociocultural y la formación de cultura ambiental: resultados de la carrera de estudios socioculturales. Revista Atlante: Cuadernos de Educación y Desarrollo, p. 1-15, marzo 2019. Disponible en: https://1library.co/document/download/q5mrox3y?page=1. Acceso en: 5 oct. 2021.

BRASIL. [Constituição (1988)]. Constituição da República Federativa do Brasil de 1988. Brasília, DF: Presidência da República, 1988. Disponível em: http://www.planalto.gov.br/ccivil_03/Constituicao/Constituicao.htm. Acesso em: 22 set. 2021.

BRASIL. Ministério da Cultura. Portaria 156, de 06 de julho de 2004. Cria o Programa Nacional de Cultura, Educação e Cidadania - CULTURA VIVA, com o objetivo de promover o acesso aos meios de fruição, produção e difusão cultural, assim como de potencializar energias sociais e culturais, visando a construção de novos valores de cooperação e solidariedade. DOU, Brasília, DF, 6 jul. 2004.

CACHO PÉREZ, Luis (org.). Derecho Cultural. México: UNAM, 2017.

CACHO PÉREZ, Luis. Los derechos culturales y la Ley de la Cultura. Investigaciones Jurídicas, México, n. 40, 2016.

CAIRO BALlESTER, Ana. Letras. Cultura en Cuba. Cuba: Pueblo y Educación. 1989.

CALlE MEZA, Melba. A propósito de la cultura constitucional. Derecho del Estado, Colombia, n. 25, 2010.

CÁNDANO PÉREZ, Mabel; MORENO CRUZ, Marta. Propiedad intelectual en Cuba: Una mirada crítica a su reconocimiento constitucional. Revista Chilena de Derecho y Tecnología, v. 8, n. 1, p. 133-165, enero/jun. 2019. Disponible en: http://dx.doi.org/10.5354/0719-2584.2019.51115. Acceso en: 5 oct. 2021.

CELEIRO CARBONELL, Felicia. La cultura ético-axiológica humanista del profesional de la educación desde la formación inicial. 2012. Tesis (Doctorado) Universidad de Ciencias Pedagógicas Frank País García, Santiago de Cuba, Cuba, 2012.

CORREAS, Oscar. Teoría del Derecho. México: Fontamara. 2004.

CUBA. Ley No. 1. Ley de Protección del Patrimonio Cultural. Gaceta Oficial de la República de Cuba, Ordinaria Nro. 29 de 1977. 
CUBA. Ley No. 2. Ley de los Monumentos Nacionales y Locales, Gaceta Oficial de la República de Cuba, Ordinaria Nro. 29 de 1977.

CUBA. Ley No. 59, Código Civil. G.O. Extraordinaria No. 9 del 15 de octubre de 1987.

CUBA. Ley No. 62, Código Penal. G.O. Especial No. 3 del 30 de diciembre de 1987.

CUBA. Ley No. 113, Ley Tributaria. G.O. Ordinaria No. 53 del 21 de noviembre de 2012.

CUBA. Decreto No. 21. Reglamento sobre la planificación física. Gaceta Oficial de la República de Cuba, Ordinaria No. 8 de 1978.

CUBA. Decreto No. 55. Reglamento para la Ejecución de la Ley No. 2 de los Monumentos Nacionales y Locales. Gaceta Oficial de la República de Cuba, 1979.

CUBA. Decreto No. 118. Reglamento para la Ejecución de la Ley de Protección al Patrimonio. Gaceta Oficial de la República de Cuba, 1983.

CUBA. Decreto-Ley No. 201. Del Sistema Nacional de Áreas Protegidas. Gaceta Oficial de la República de Cuba, 1999.

CUBA. Decreto No. 272. Contravenciones en materia de ordenamiento territorial y urbanismo. Gaceta Oficial de la República de Cuba, 2001.

CUBA. Decreto-Ley No. 331. De las Zonas con Regulaciones Especiales. Gaceta Oficial de la República de Cuba, 2015.

CUBA. Decreto Ley No. 370. Sobre la informatización de la sociedad en Cuba. G. O. No. 45. Edición ordinaria. del 4 de julio 2019.

CUBA. Decreto Ley No. 373. Del Creador Audiovisual y Cinematográfico Independiente. G. O. Ordinaria del 27 de junio de 2019.

CUBA. Ministerio de Educación Superior. Plan de Estudios E, Carrera Licenciatura en Gestión Sociocultural para el Desarrollo. Cuba, 2017.

CUBA. Constitución de la República de Cuba. Gaceta Oficial, no 5 Extraordinaria de 10 de abril de 2019. Disponible en: https://www.gacetaoficial.gob.cu/sites/default/files/goc-2019-ex5_0.pdf. Acceso en: 22 set. 2021.

DE LUCA, Javier. Introducción al Derecho. 3. ed. España: Tirant Lo Blanch, 1997.

DEL VECCHIO, Giorgio. Filosofía del Derecho. España: Bosch, 1980.

DEL REAL ALCALÁ, José. El derecho a la identidad cultural: criterios de fundamentación. Derechos y Libertades, España, n. 29, 2013.

DIETERICH, Heinz. Globalización, cultura e identidad nacional. Cuba: Ciencias Sociales, 2002. 
La gestión sociocultural para el desarrollo en Cuba y Brasil: un estudio desde el derecho constitucional cultural

DORANTES DÍAZ, Francisco. El derecho a la cultura. Derecho y Cultura. Jurídicas, $2001 . \quad$ Disponible en: http://www.juridicas.unam.mx/publica/librev/rev/derycul/cont/4/ens/ens12.pdf. Acceso en: 22 set. 2021.

ESPINOSA RAMÍREZ, José. Gestión de la cultura profesional en la educación superior. 2008. Tesis (Doctorado en Ciências Pedagógicas). Cuba: Universidad de Granma, 2008.

FABELO CORSO, José. Los valores y sus desafíos actuales. Cuba: Ciencias Sociales, 2004.

FERNÁNDEZ BULTÉ, Julio. Historia del Estado y el Derecho en Cuba. Cuba: Félix Varela, 2007.

FERRAJOLI, Luigi. Derechos y garantías. La ley del más débil. España: Trotta, 2004.

FREIRE, Paulo. Pedagogía del oprimido.2. ed. México: Siglo XXI, 2005.

FREUD, Simung. El malestar de la cultura. Obras completas. España: Biblioteca Nueva, 1981.

FREUND, Julien. La esencia de lo político. España: Nacional, 1968.

FRESNO CHÁVEZ, Caridad. La formación de valores: reto del siglo XXI. Cuba: Universitaria, 2017.

FORNET, Ambrosio. Cultura e identidad nacional. Memorias del encuentro Cuba: cultura e identidad nacional. Cuba: Unión, 1995.

FUENTES, Homero. Pedagogía y Didáctica de la Educación Superior, en la concepción de la Universidad humana y cultural, una propuesta desde la Universidad Estatal de Bolívar. Ecuador: INDUGRAF, 2009.

GARCÍA CÍVICO, Jesús. Derecho y cultura: una dimensión cultural del derecho. Anuario de la Facultad de Derecho, n. 11, 2018.

GARCÍA LORENZO, Tania. La cultura en el desarrollo y la producción cultural en el desarrollo económico. Cuba: Laboratorio de Prácticas Culturales Sostenibles del ISA, 2014.

GARCÍA MÁYNEZ, Eduardo. Positivismo jurídico, realismo sociológico y iusnaturalismo. México: Biblioteca de ética, filosofía del Derecho y política, 1999.

GEERTZ, Carlos. La interpretación de las culturas. España: Gedisa, 2003.

GOMES, Magno Federici; FERREIRA, Leandro José. A dimensão jurídico-política da sustentabilidade e o direito fundamental à razoável duração do procedimento. Revista do Direito, Santa Cruz do Sul, n. 52, v. 2, p. 93-111, maio/set. 2017. Disponible en: http://dx.doi.org/10.17058/rdunisc.v2i52.8864. Acceso en: 22 set. 2021. 
GOMES, Magno Federici; FERREIRA, Leandro José. Políticas públicas e os objetivos do desenvolvimento sustentável. Revista Direito e Desenvolvimento, João Pessoa, v. 9, n. 2, p. 155-178, ago./dez. 2018. Disponible en: https://doi.org/10.25246/direitoedesenvolvimento.v9i2.667. Acceso en: 2 jun. 2021.

HÄBERLE, Peter. La Constitución como cultura. Iberoamericano de justicia constitucional, España, n. 6, 2002.

HABËRLE, Peter. Aspectos constitucionales de la identidad cultural. Derechos y Libertades, $\mathrm{n}^{\circ} 14,2006$.

HART DÁVALOS, Armando. Cultura general integral masiva o anarquía social. Rev Bohemia, v. 93, n. 19, p. 60-65, 2001.

HART DÁVALOS, Armando. Ética, cultura y política. México: UNAM. 2004.

HART DÁVALOS, Armando. ¿Qué es la cultura? Honor, La Habana, n. 11, 2004.

HART, Herbert. Utilitarismo y derechos naturales. Traducción de Everaldo Lamprea Montealegre. Bogotá: Universidad Externado, 2003.

HARVEY, Edwin. Derechos culturales. Brasília: UNESCO, 1995.

HORRUITINIER SILVA, Pedro. La universidad cubana: el modelo de formación. Cuba: Universitaria, 2009.

HORRUTINIER SILVA, Pedro. La Universidad Cubana en la época actual. Universalización y Cultura Científica para el Desarrollo Local. Cuba: Félix Varela, 2007.

JESÚS MOREIRA, M. El concepto de cultura en el derecho. Civitas, España, n. 3, 2008.

TAJADURA, Javier. La constitución cultural. Derecho Político, Colombia, n. 43, 1998.

KANT, Inmanuel. La metafísica de las costumbres. España: Tecnos, 1994.

KELSEN, Hans. Teoría Pura del Derecho. México: Porrúa, 1993.

KYMLICKA, Will. La política vernácula: nacionalismo, multiculturalismo y ciudadanía. España: Paidós, 2003.

MARAÑA, Mayder. Derechos culturales. Documentos básicos de Naciones Unidas. UNESCO: Paris, 2010.

MARTÍ, José. Obras Completas. La Habana: Ciencias Sociales, 1973. t. 8.

MARTINELL SAMPERE, Alfons. La gestión cultural: singularidad profesional y perspectivas de futuro. Paris: UNESCO, 2001.

MARTINELL SAMPERE, Alfons. Los agentes culturales ante los nuevos retos de la gestión cultural. Iberoamericana de Educación, España, n. 20, 1999. 
La gestión sociocultural para el desarrollo en Cuba y Brasil: un estudio desde el derecho constitucional cultural

MARTÍNEZ CASANOVA, Manuel. Introducción a la Gestión Sociocultural para el Desarrollo. La Habana: Félix Varela, 2015.

MELERO DE LA TORRE, Mariano. Cultura constitucional. Eunomía, España, n. 15, 2018.

MONTERO MOYA, Fredy. Los derechos culturales: un acercamiento a su contenido programático y aplicabilidad normativa. Cuadernos de Antropología, España, n. 14, 2004.

NAVARRO, Desiderio. Cultura y marxismo. Problemas y polémicas. Cuba: Letras Cubanas, 1986.

NOGUERA FERNÁNDEZ, Albert. El sistema político institucional en la nueva Constitución cubana de 2019: ¿continuidad o reforma?. Catalana de Dret Públic, España, n. 59, 2019.

NUIRY SÁNCHEZ, Nuria (org.). Pensamiento y política cultural cubana. Cuba: Pueblo y Educación, 1986.

ONU. Declaración Universal de Derechos Humanos y Pacto Internacional de los Derechos Económicos, Sociales y Culturales. 1948. Disponible en: http://www.ohchr.org/SP/ProfessionalInterest/Pages/CESCR.aspx. Acesso em: 22 set. 2021.

ONU. Declaración Universal de los Derechos Humanos. 1948. Disponible en: http://www.un.org/es/documents/udhr/. Acesso em: 22 set. 2021.

PECES-BARBA, Gregorio. Lecciones de Derechos Fundamentales. España: Dykinson, 2005.

PEGORARO, Lucio. Constitucionalización del derecho y cultura constitucional. Derecho Político, Colombia, n. 104, 2019.

PÉREZ GALLARDO, Leonardo. Cultura y cultura popular. Influencia recíproca: África, España, Francia, China e Iberoamérica. El derecho como saber cultural. Cuba: Universidad de La Habana, 2011.

PÉREZ LUÑO, Antonio. Los derechos fundamentales. España: Tecnos, 2004.

POGOLOTTI, Graciela. Polémicas culturales de los 60. Cuba: Letras Cubanas, 2006.

PORTUONDO, Fernando. La cultura entre los mambises del 68. Estudios de Historia de Cuba. Cuba: Ciencias Sociales, 1973.

PRIETO DE PEDRO, Jesús. Cultura, Culturas y Constitución. España: CEC, 1993.

PRIETO DE PEDRO, Jesús. El Derecho de la cultura. España: Universidad Oberta de Catalunya, 2010.

PRIETO VALDÉS, Martha. El ordenamiento jurídico cubano. Cuba: Félix Varela, 2003. 
PUEBLA RODRÍGUEZ, Martha (org.). Actualidad de la formación de la cultura estética en las carreras estudios y gestión sociocultural para el desarrollo. Roca, Cuba, n. $1,2019$.

PUENTE, Stela. Industrias Culturales. Argentina: Prometeo Libros, 2007.

ROCHA, S. C.; ARAGÃO, A. L. Direitos Culturais no Brasil e uma breve análise do programa Cultura Viva. In: SEMINÁRIO INTERNACIONAL DE POLÍTICAS CULTURAIS, 2., 2011, Rio de Janeiro. Anais [...]. Rio de Janeiro: Fundação Casa de Rui Barbosa, 2011.

RODRÍGUEZ, Carlos. Letra con Filo. Cuba: Unión, 1987.

RODRÍGUEZ, Joaquín. Derechos culturales. Diccionario Jurídico Mexicano. 10. ed. México: Porrúa, 1997.

ROMANO, Santi. El ordenamiento jurídico. España: Instituto de Estudios Políticos, 1963.

RUIZ MIGUEL, Carlos. El Constitucionalismo cultural. Cuestiones Constitucionales, Chile, n. 9, 2003.

RUIZ ROBLEDO, Agustín. La Constitución cultural en España. España: Instituto Andaluz de Administración Pública, 1998.

SARDA, Eduardo; LLOGA, Carlos. ¿Constitución cultural en Cuba? aciertos y desaciertos de la regulación jurídica de la cultura en la nueva constitución cubana. Catalana de Derecho, España, n. 61, 2020

STAVENHAGEN, Rodolfo. Educación y Derechos Culturales: Un Desafío. In: COLOQUIO INTERNACIONAL DE EDUCACIÓN EN DERECHOS HUMANOS Y ENCUENTRO LATINOAMERICANO, 6., 2002, México. Anais [...]. México, 2002.

TERRÓN QUINTERO, Grisel. La colección facticia de Emilio Roig de Leuchsenring: un análisis integral de sus valores patrimoniales como cuerpo documental en el contexto histórico cultural cubano. 2015. Tesis doctoral- Universidad de Granada, España, 2015.

TÜNNERMAN BERNHEIM, Carlos. La educación superior en el umbral del siglo XXI. UNESCO, 2009.

TYLOR, Edward. Primitive culture. Londres: John Murray, 1871.v. 1.

UNESCO. Conferencia Mundial sobre las Políticas Culturales. México, 1982.

UNESCO. Formación en Gestión Cultural y Políticas Culturales. Paris, 2005.

UNESCO. Informe mundial de la UNESCO. Invertir en la diversidad cultural y el diálogo intercultural. Paris, 2009.

VYGOTSKY, Leontiev. Pensamiento y lenguaje: teoría del desarrollo cultural de las funciones psíquicas. Cuba: Pueblo y Educación, 1987. 
La gestión sociocultural para el desarrollo en Cuba y Brasil: un estudio desde el derecho constitucional cultural

YANES CANAL, Carlos (org.). Praxis de la gestión cultural. Colombia: Universidad Nacional, 2018.

WEBER, Max. Economia e societá III: Sociologia del diritto. Italia: di Comunitá., 1995.

\section{NOTA}

Os autores Ana, Alcides e Magno participaram em conjunto e de forma complementar para a concretização do presente artigo. A coautora Ana definiu o tema, o problema, os objetivos, a metodologia, a organização e a revisão do artigo. Ademais, elaborou o capítulo 3. O coautor Alcides trouxe fundamentos teóricos a todos os capítulos, elaborou a introdução, o capítulo 2 e as conclusões. $\mathrm{O}$ coautor Magno elaborou os resumos, redigiu a parte relacionada com o Brasil, trouxe fundamentos teóricos a todos os capítulos, revisou todas as citações e aplicou a normalização da ABNT/Brasil utilizada pela revista. $\mathrm{O}$ artigo que ora se propõe é, portanto, uma obra de cunho coletivo.

\section{Como citar este documento:}

VÁZQUEZ, Ana Elisa Gorgoso; SÁNCHEZ, Alcides Francisco Antúnez; GOMES, Magno Federici. La gestión sociocultural para el desarrollo en Cuba y Brasil: un estudio desde el derecho constitucional cultural. Revista Opinião Jurídica, Fortaleza, v. 20, n. 33, p. 135-164, jan./abr. 2022. 